\title{
Low-output heart failure: A review of clinical status and meta-analysis of diagnosis and clinical management methods
}

\author{
Aref Albakri* \\ Department of Internal Medicine, St-Marien hospital Bonn Venusberg, Bonn, Germany
}

\begin{abstract}
Low-output heart failure (LoHF) is an uncommon form of heart failure (HF) but one that signals very advanced HF. It is associated with ominous prognosis as well as substantial morbidity and mortality. However, LoHF remains largely under-researched. The traditional description of $\mathrm{HF}$ focused on congestive heart failure (CHF) marked by low cardiac output and accompanied by pulmonary/peripheral congestion. This focus contributed to under-appreciation of LoHF patients who have little or no evidence of congestion. Moreover, LoHF patients have no proven therapy and the selection of appropriate treatment depends on individual pathophysiology and underlying aetiology. LoHF patients have heterogeneous aetiology and pathophysiology highlighting the importance of in-depth understanding of its clinical features, diagnosis and clinical management, which forms the basis of the present review.
\end{abstract}

\section{Introduction}

Despite remarkable advancements in medical and surgical therapies, effective management of heart failure (HF) continues to pose significant challenges to healthcare providers. The challenge is reflected by high rates of HF-related hospital readmissions along with increased mortality and morbidity [1]. Part of the challenge is very heterogeneous aetiology, pathophysiology, and clinical presentations of different forms of HF, in which some HF forms have a paucity of clinical trial data and consequently a limited understanding. In particular, the traditional description of HF has been almost synonymous with congestive heart failure (CHF) yet the term CHF excludes a minority of HF patients who have little or no demonstrable symptoms of pulmonary and/or peripheral congestion [2]. Low-output HF (LoHF) has also been linked with an ominous prognosis and signals very advanced HF. Moreover, symptomatic and pathophysiological differences in CHF and LoHF support the need for different clinical management approaches [3]. Despite these differences, traditional HF therapies have been generalized to all forms of HF including CHF and LoHF, creating a clinical need to understand the pathophysiology, diagnosis and clinical management of LoHF. In this article, we aggregate published evidence on LoHF in terms of epidemiology, aetiology, pathophysiology, diagnosis and clinical management. The intention is to revamp the knowledge of the clinical status of LoHF as well as improve clinical management of HF in general.

\section{Definition}

Heart failure is a complex clinical syndrome marked by structural and/or functional myocardial defects leading to impaired ventricular filling or ejection $[4,5]$. The complexity of the syndrome is evident in its heterogeneous classifications: right-, left- or bi-ventricular based on defect location; acute or chronic based on time of onset; preserved, borderline or reduced ejection fraction based on functional status; low- or high-output based on cardiac output (CO), and forward or backward failure based on the direction of blood flow. Each of these classifications is significant for the diagnosis and treatment of HF [4,5]. Despite the several classifications, the term CHF has traditionally been used interchangeably with HF but which does not sufficiently describe LoHF because of several symptomatic and pathophysiological differences.

LoHF, also known as low CO in acute decompensated HF, describes a high-acuity form of $\mathrm{HF}$ characterized by decreased forward $\mathrm{CO}$ (cardiac index $[\mathrm{CI}]<2.0 \mathrm{~L} / \mathrm{min} / \mathrm{m}^{2}$ and systolic blood pressure $[\mathrm{BP}]<$ $90 \mathrm{mmHg}$ ) and end-organ hypoperfusion with little or no evidence of pulmonary congestion [6]. LoHF is distinct from CHF, which describes HF characterized by reduced $\mathrm{CO}$ causing to pulmonary and peripheral congestion leading to dyspnoea and peripheral oedema respectively [7]. The 2005 European Society of Cardiology (ESC) guidelines on diagnosis and management of HF [8] suggest a continuum from low cardiac output syndrome (LCOS) to LoHF to cardiogenic shock. The ESC guidelines define cardiogenic shock as evidence of tissue perfusion induced by HF after the correction of pre-load characterized by systolic $\mathrm{BP}<90 \mathrm{mmHg}$ or a drop of mean arterial pressure $>30$ $\mathrm{mmHg}$; urine output $<0.5 \mathrm{ml} / \mathrm{kg} / \mathrm{h}$; pulse rate $>60$ beats per minute (bpm) with or without evidence of congestion [8]. LCOS on the other hand is common in post-operative HF patients and defined as the need for post-operative intra-aortic balloon pump or inotropic support for greater than 30 minutes in an acute care setting [6].

${ }^{\star}$ Correspondence to: Aref Albakri, Department of Internal Medicine, St-Marien Hospital Bonn Venusberg, Bonn, Germany, E-mail: arefalbakri@yahoo.com

Key words: low-output cardiac syndrome, low-output heart failure, low-output state

Received: January 31, 2019; Accepted: February 15, 2019; Published: February 20, 2019 


\section{Epidemiology}

The exact prevalence and incidence of LoHF in the general population is completely unknown. At present, there are no populationbased epidemiological data specific to LoHF. The only available data are from single-centre clinical trials investigating a select population of HF patients who have undergone cardiac surgery. In 1975, Parr et al. [9] made the seminal description of the clinical entity of LCOS and reported an incidence of $25 \%$ in children who had undergone cardiac surgery based on decreased CO defined as $\mathrm{CI}<2.0 \mathrm{~L} / \mathrm{min} / \mathrm{m}^{2}$. Two decades later, Wernovsky et al. [10] demonstrated the same incidence of post-operative LCOS in patients who had undergone arterial switch operation occurring within 6-18 hours post-surgery. Much recent clinical trials report a wide variation in prevalence, from $3.6 \%$ (men) and $5.9 \%$ (women) [11] to $9.1 \%$ [12] and to $41 \%$ [13] and an incidence of $14.7 \%$ [14]. In a recent long-term (twenty-year: 1990-2009) prospective clinical trial involving 25,176 consecutive coronary artery by-pass graft (CABG) surgery patients, Algarni et al. reported the prevalence of postoperative LCOS decreased significantly from 9.1\% (1990-1994) to $2.4 \%$ (2005-2009) [15].

\section{Aetiology}

The aetiology of LoHF is multi-factorial. Generally, it is a consequence of left ventricle (LV), right ventricle (RV) or systemic ventricle (single ventricle anatomy) dysfunction and can include either or both systolic and/or diastolic dysfunction [16]. Perturbations in ventricular filling or ejecting lead to LoHF, which is a frequent complication in patients who have undergone cardiac surgery or are in cardiogenic shock [6]. It may present as an acute deterioration in patients with chronic HF or it may be transient and reversible episode with resolution of the acute trigger. It is a clinical syndrome considered the final pathway of a multitude of diseases affecting cardiac function. It is not sufficient to make diagnosis of LoHF, the underlying cause or trigger must also be determined, and if possible, treated [16,17]. Table 1 provides a summary of conditions causing low-output state in HF patients.

\section{Pathophysiology}

The current understanding of the pathophysiology of LoHF largely relies on the evidence from clinical trials on post-operative CABG patients [9-12]. The pathologic hallmark is excessively depressed CO accompanied by end-organ hypoperfusion. Physiologically, the heart functions as a pump to distribute oxygenated blood in sufficient quantities to satisfy metabolic needs of tissues. Since metabolic needs vary under normal and stressful situations, $\mathrm{CO}$ also varies to satisfy this dynamic demand [18]. The diastolic phase of the cardiac cycle is critical in LoHF patients because it is during ventricular relaxation that coronary filling occurs to provide myocardial oxygenation [19]. Heart rate (HR) is also significant in diastole because too rapid HR prevents the heart from achieving complete myocardial relaxation and perfusion. Thus, cardiac dysfunction results from structural (residual cardiac anomaly) or functional cardiac disorder (disturbances in ventricular filling or emptying, or increased systemic vascular resistance [SVR]).

Pathophysiologically, CO is dependent on the HR and the stroke volume $(\mathrm{SV})\left(\mathrm{CO}=\mathrm{HR}{ }^{\star} \mathrm{SV}\right)$. Stroke volume in turn is the net product of three inter-related circulation variables: preload, afterload and contractility. If one or more of these components is impaired, a lowcardiac output state can develop [6]. Moreover, these components affect both systolic and diastolic phases of the cardiac cycle causing LV/RV systolic dysfunction and/or diastolic dysfunction also known as HF with preserved ejection fraction (Figure 1). Other conditions such as valvular heart disease, pulmonary hypertension $(\mathrm{PH})$, mechanical valve dysfunction, and respiratory failure can precipitate or aggravate the development of LoHF [17].

\section{LV ystolic dysfunction}

Left ventricular (LV) systolic dysfunction (or depressed LV ejection fraction [LVEF]) is the most common pathophysiologic mechanism seen in LoHF patients. Circulation variables affecting LV systolic function are preload, after load, and contractility [17]. Generally, LV systolic dysfunction is a consequence of the loss or reduction of functional cardiomyocytes resulting from necrosis due to impaired coronary circulation and ischemia, reperfusion injury or the less understood natural phenomenon of cardiomyocyte apoptosis [20-22]. The loss of functional cardiomyocytes can be transient as seen during myocardial stunning defined as a viable myocardium salvaged by coronary reperfusion, which exhibits prolonged post-ischemic dysfunction following reperfusion [23]. The loss of functional cardiomyocyte can also be refractory to reversal in conditions such as infection; tachycardia; valvular disease; metabolic disorders such as acidosis, hypoglycemia, hypocalcaemia; exposure to environmental cardiac toxins and chemicals; idiopathic dilated cardiomyopathy (DCM); and genetic disorders such as familial DCM, hypertrophic cardiomyopathy and muscular dystrophies [17]. Impaired cardiac response to preload causes a dramatic decrease in $\mathrm{CO}$ and oxygen delivery to other key body organs, elevated atrial pressure, capillary wedge pressure, and cardiogenic pulmonary oedema. Although compensatory changes in the LV adapts to relatively high systemic arterial pressure, significant increase in afterload can induce LV systolic dysfunction [17].

\section{LV diastolic dysfunction}

Although uncommon, LoHF can develop in patients with LV diastolic dysfunction with preserved LVEF. The condition results from the inability of the ventricular chamber to fill with adequate volume of blood despite normal preload, which presents as diastolic dysfunction [24]. Underlying conditions such as severe tachycardia, decreased myocardial compliance, or abnormal ventricular relaxation impairs the relaxation and filling of the LV during the diastole phase of cardiac cycle. At the cardiomyocyte level, these conditions are associated with calcium removal from the cytosol and calcium homeostasis, the adequacy of cross-bridge detachment and intrinsic functional

Table 1. Aetiology of low-output state by pathophysiology

\begin{tabular}{|l|l|}
\hline Mechanisms & Causative Conditions \\
\hline Loss of myocardial contractility & $\begin{array}{l}\text { Coronary artery disease, cardiomyopathy, myocarditis, decompensated chronic HF, post-cardiac surgery, toxins, nutrition (obesity)m } \\
\text { infiltrative diseases, end stage renal failure, Chagas disease or HIV infection }\end{array}$ \\
\hline Impaired ventricular filling or ejecting & $\begin{array}{l}\text { Pericarditis, pericardial effusion, cardiac tamponade, tension pneumothorax, pulmonary embolism, valvular disease, hypertension, volume } \\
\text { overload, cardiomyopathy (hypertrophic/restrictive) }\end{array}$ \\
\hline Abnormal Signalling & Tachyarrhythmia, bradyarrhythmia, \\
\hline Non-cardiovascular factors & Infection, sepsis, major surgery, asthma, severe brain injury \\
\hline High output states & Thyrotoxicosis (hyperthyroidism), sepsis, anaemia, arteriovenous shunting \\
\hline
\end{tabular}




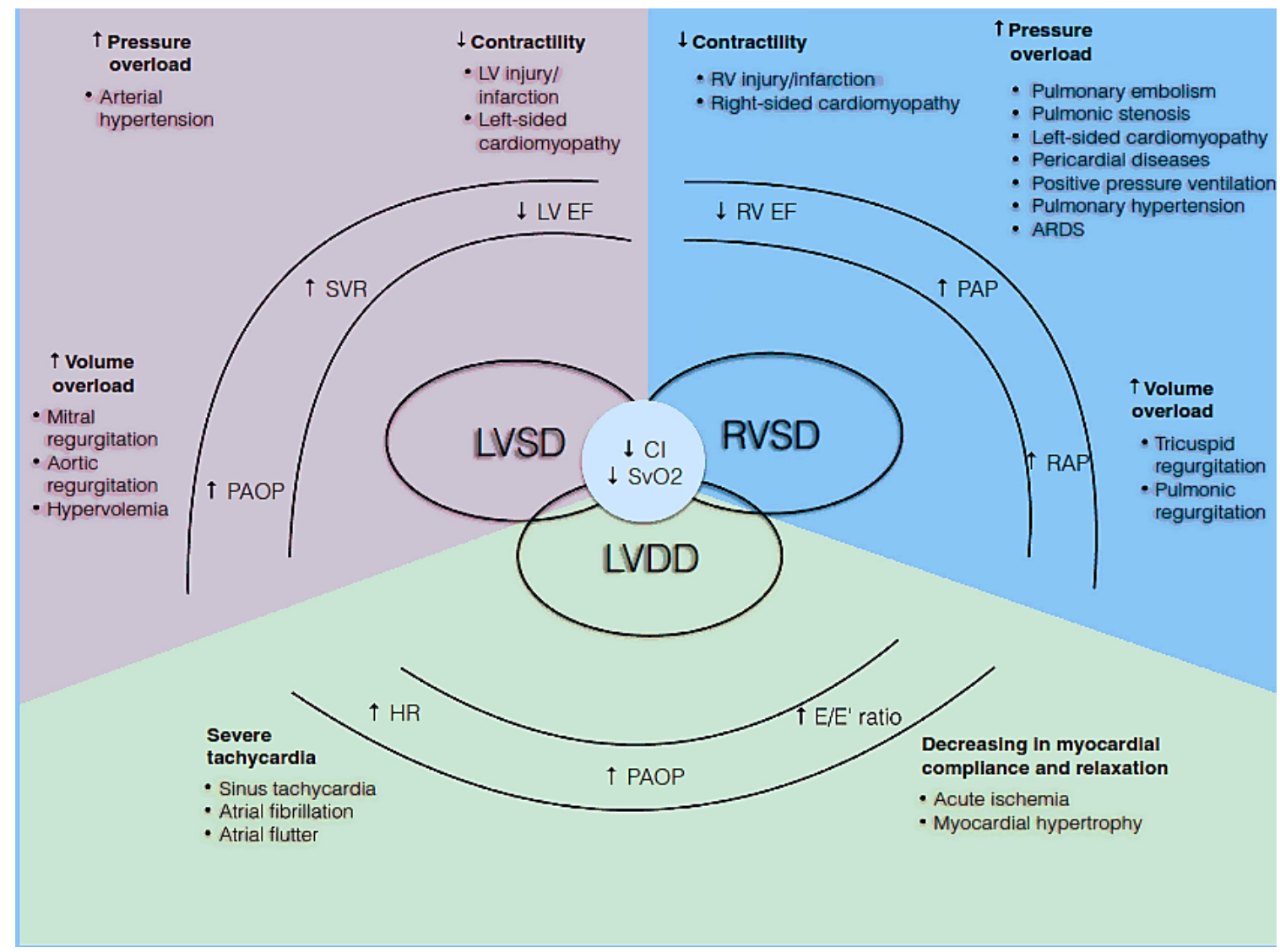

Figure 1. Pathophysiologic mechanisms of low-output heart failure

Common causes and typical; symptoms of LoHF are included. The major pathophysiological mechanisms of LoHF is ventricular dysfunction: LV systolic and/or diastolic dysfunction and $\mathrm{RV}$ systolic dysfunction, all of which share common pathologic features of reduced cardiac index $(\mathrm{CI})$ and reduced mixed venous oxygen saturation $\left(\mathrm{SvO}_{2}\right)$. $\mathrm{LV}$ and $\mathrm{RV}$ systolic dysfunction results from increased pressure overload, increased volume overload and decreased contractility while LV diastolic dysfunction results from severe tachycardia and decreased myocardial compliance and relaxation. Adapted from Lomivorotov et al. 2017, p. 293 [17]

cytoskeletal element disorder [25]. Cross-bridge detachment can contribute to delayed isovolumic relaxation time, which results in decreased LV stroke volume especially at higher HR [26]. LV relaxation also depends on sarcoplasmic reticular calcium ion re-uptake and nitric oxide signalling, which also facilitate cross-bridge detachment. Since the process of cross-bridge detachment is energy consuming, it can cause a deficit in myocardial energy and consequently slow down LV myocardial relaxation $[27,28]$.

Despite diastolic dysfunction being a widespread phenomenon seen in up to $70 \%$ of post-operative cardiac patients $[29,30]$, diastolic dysfunction alone is insufficient to explain the development of acute HF. In the setting of other clinical conditions such as atrial fibrillation (AF), impaired coronary circulation, and arterial hypertension, diastolic dysfunction can result in decompensated state, and thus believed to be an early sign of myocardial ischemia [17]. The dynamic relationship between the LV diastolic and systolic functions also contributes to diastolic dysfunction in LoHF patients. Stimulation of inotropic catecholamine affects both diastole and systole, and can enhance diastolic dysfunction. Depressed LVEF leads to an increase in end-systolic volume and prolongs the diastolic phase of the cardiac cycle [17].

\section{RV dysfunction}

In LoHF, particularly after coronary artery surgery, the principle pathophysiologic mechanisms of RV dysfunction include increased preload, increased afterload, impaired right coronary artery perfusion and decreased contractility [31-33]. In contrast to left coronary artery, the perfusion of the right coronary artery occurs during both diastole and systole. The presence of $\mathrm{PH}$ causes an increase in RV pressure leading to decreased right coronary artery perfusion, which explains the importance for providing optimal left and right coronary circulation [17]. In patients who have undergone coronary artery surgery, RV dysfunction can develop as the result of a combination of mechanisms. Perioperative RV ischemia and infarction are the major causes of impaired RV contractility. Tricuspid or pulmonic regurgitation re common causes of increased volume preload while leftsided valvular disease or cardiomyopathy, $\mathrm{PH}$ or pulmonary embolism $(\mathrm{PE})$, acute respiratory distress syndrome and high positive pressure ventilation are common causes of pressure overload [34]. Since the RV normally allows low-pressure perfusion of the pulmonary vasculature, it is highly sensitive even to moderate increases in pulmonary artery pressure (PAP). RV failure can develop in the setting of $\mathrm{PH}$ or impaired contractility associated with a rapid progression of RV dilation leading to increased end-diastolic RV pressure [35]. These physiologic alterations can cause inter-ventricular septum shift towards an already under-filled LV chamber and consequently cause a reduction in LV preload and a decrease in $\mathrm{CO}$ [36].

\section{Risk Factors}

Risk factors for LoHF remains an under-researched area. However, little data available from clinical trials on HF [37] and from post- 
operative LCOS patients [9-12, 38-39] provide valuable insights into risk factors and predictors of LoHF. In analysis of 452 patients hospitalized with decompensated HF and low cardiac output, significant risk factors for LoHF were Chagas disease (Relative risk [RR]: 3.66), depressed ejection fraction (RR: 2.41), hyponatremia (RR: 1.62) and renal dysfunction (RR: 1.92) [37]. Risk factors for post-operative LoHF include impaired LV function $(<50 \%)$, on-pump CABG, emergency or cardiopulmonary bypass $(\mathrm{CPB})$ surgery, incomplete revascularization, age $>65$ years, and a combined presence of diabetes mellitus and preoperative renal dysfunction [9-12. Malnutrition is another important risk factor associated with increased the likelihood of post-operative inotropic support and independently predicts adverse post-operative clinical outcomes [40]. In addition to patient and operation risk factors, biochemical predictors of LoHF in post-operative patients are low haemoglobin levels [41], total lymphocyte count $<2000$ cells $/ \mu \mathrm{L}$ [42], and pre-operative levels of serum natriuretic peptides [43,44]. Over the past two decades, there have been changes in the trends in some recognised risk factors. Factors such as hypertension, female sex, triple vessel disease and left main disease are no longer statistically significant while the risk associated with depressed pre-operative ejection fraction has doubled [15].

\section{Diagnosis}

There is no consensus guidelines or proven diagnostic criteria for LoHF patients. In addition, clinical signs and symptoms are nonspecific. In the absence of standardized guidelines, diagnosis usually relies on accepted collection of hemodynamic and physiologic aberrations useful for raising clinical suspicion of LoHF [16]. Diagnosis of LoHF alone is often not enough. The cause of the low-output state also has to be established. In some causes of low-output state such as PE or $\mathrm{MI}$, treating the underlying cause is the most important consideration and thus it is imperative to make the diagnosis. Since LoHF patients are often unstable, it is also common for clinical evaluation, diagnosis and treatment to occur concurrently more so in acute care settings [4].

\section{Signs and symptoms}

Low cardiac output as the presenting feature of acute decompensated HF is uncommon, affecting only 8.9 to $9.6 \%$ of hospitalized HF patients $[45,46]$. LoHF may share many clinical features with CHF but there are notable differences that may support or guide subsequent diagnostic decisions. Excessive fatigue and increased exercise intolerance are important initial signs noticed by LoHF patients even prior to diagnosis $[4,5]$. In addition, LoHF patients commonly present with agitation, confusion and/or reduced levels of consciousness; cold/vasoconstricted peripheries or delayed capillary refill time; hypotension; tachycardia or bradycardia; thready pulse; raised jugular venous pressure; breathlessness and hypoxaemia; and oliguria/anuria [3,4]. These signs and symptoms can differ between low perfusion and congestion in HF patients (Table 2).

\section{Initial clinical evaluation}

History and physical examination: The 2016 ESC guidelines on diagnosis and management of HF emphasize on the importance of obtaining detailed patient history and physical examination on all patients suspected to have HF [4]. Detailed history from the patient, or relative and friends if the patient is too unwell, should focus on obtaining information about symptoms, previous and current cardiac and extra-cardiac conditions capable of precipitating or aggravating HF, exposure to risk factors of HF or of low-output state, and medication history for previous and current medical conditions [4]. In addition to patient history, physical examination is recommended to all LoHF patients to assess for clinical indicators for hemodynamic, peripheral perfusion, congestion, underlying aetiology and valvular pathology. Hemodynamic parameters of interest include blood pressure, HR and heart rhythm, gallop rhythm, oxygen saturation, and respiratory rate [47]. Tests for peripheral perfusion should include consciousness levels, peripheral skin/central temperature, capillary refill time, and urine output. Tests for congestion include raised jugular venous pressure, peripheral/pulmonary oedema, hepatomegaly, ascites and pleural effusions. Tests for the underlying aetiology should incorporate cardiovascular examination, and heart sound and murmurs. Finally, evidence for valvular dysfunction should include pericardial rub and evidence of pericardial effusion with or without cardiac tamponade [48].

The combination of patient history and physical examination have proven invaluable in the assessment of hemodynamic status and recognition of LoHF [49]. In 1976, Forrester et al. [50] conducted physical examination of patients with acute myocardial infarction and identified four hemodynamic profiles (A, B, L and C) as illustrated in Figure 2. Hemodynamic profiles are based on presence or absence of pulmonary congestion (pulmonary capillary wedge pressure [PCWP] $>$ or $\leq 18 \mathrm{mmHg}$ ) and the adequacy of perfusion $\left(\mathrm{CI}>2.2 \mathrm{~L} / \mathrm{min} / \mathrm{m}^{2}\right)$. Profile A represents no congestion/hypoperfusion; Profile B congestion without hypoperfusion; Profile C hypoperfusion without congestion;

Table 2. Symptoms and signs of low perfusion vs. congestion in heart failure patients

\begin{tabular}{|c|c|}
\hline Low Perfusion & Congestion \\
\hline Fatigue & Fatigue \\
\hline Confusion & Tachycardia \\
\hline Agitation & Raised jugular venous pressure \\
\hline Low level of consciousness & Breathlessness and hypoxemia \\
\hline Cold peripheries & Pulmonary oedema \\
\hline Delayed capillary refill time & Lowe extremities oedema \\
\hline Thready pulse & Hepatic congestion \\
\hline Hypotension & \\
\hline Tachycardia & \\
\hline Oliguria or anuria & \\
\hline Metabolic acidosis & \\
\hline $\mathrm{SvO}_{2}<65 \%$ & \\
\hline
\end{tabular}

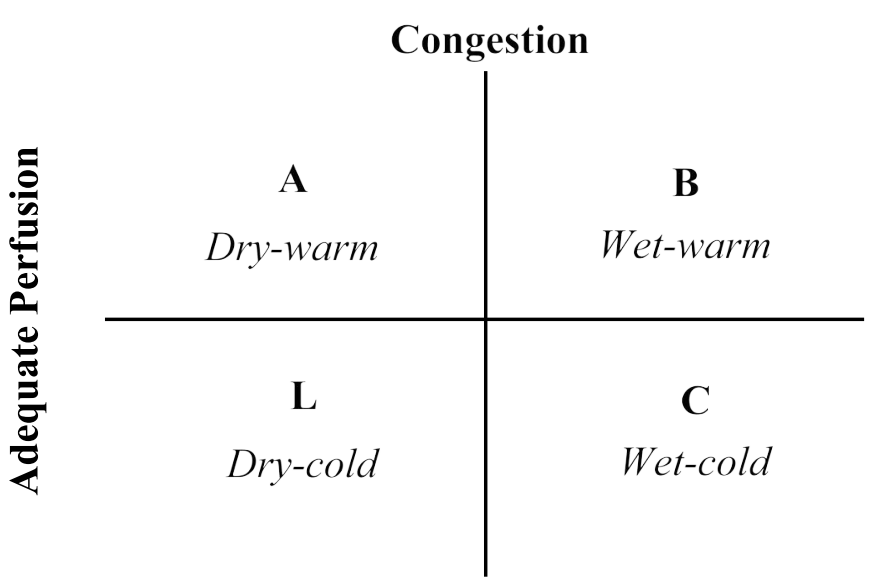

Figure 2. Schematic presentation of clinical profile of acute decompensated heart failure Congestion is assessed by the presence of orthopnoea, jugular venous distension, pulmonary rales, hepatojugular reflux, ascites, peripheral oedema, abdominal reflux and Valsalva square wave. Low perfusion was assessed by the presence of a narrow pulse pressure, pulsus alterations, cold extremities, maybe sleepy, declining serum sodium levels and worsening renal function. Adapted from Nohria, et al. [47] 
and Profile L congestion and hypoperfusion [51]. LoHF patients fall under Profiles L and C (hypoperfusion \pm congestion based on Nohria et al. [49] demonstration that Profile $\mathrm{L}$ and $\mathrm{C}$ have an average CI of 1.6 $\mathrm{L} / \mathrm{min} / \mathrm{m}^{2}$ and $1.9 \mathrm{~L} / \mathrm{min} / \mathrm{m}^{2}$ respectively.

Electrocardiogram (ECG): Both AHA [4] and ESC [5] guidelines on HF recommend that electrocardiogram (ECG) should be performed as early as possible in all patients suspected with HF. ECG can demonstrate a variety of abnormalities and is very unlikely to be normal in HF patients. It may also provide evidence of an underlying aetiology of cardiac dysfunction including bradycardia, atrioventricular block, sinus tachycardia, atrial or ventricular tachyarrhythmia, ischemia, LV hypertrophy and low voltage complexes [5].

Basic laboratory tests: The AHA and ESC HF guidelines [4,5] also recommend basic laboratory tests in the initial clinical evaluation to support diagnosis of HF or of the cause of the low-output state. Blood tests should be performed in all suspected HF patients. Haemoglobin $(\mathrm{Hb}>10 \mathrm{~g} / \mathrm{dL}$ ) indicates optimal oxygen delivery to tissues), chronic anaemia is common in chronic HF and markedly increased white blood cells raise the suspicion for alternative diagnosis. Tests for serum electrolyte to determine levels of potassium, magnesium and calcium. Urea and creatinine tests to assess renal hypoperfusion and dysfunction common in HF. Tests for impaired liver function, which suggest impaired RV and/or hepatic congestion. Glucose test to assess for hypoglycaemia that can impair cardiac function. Thyroid function tests for hypo- or hyper-thyroidism that can cause intrinsic myocardial infarction. Finally, tests for serum natriuretic peptides whose elevated levels indicate increased ventricular wall stress but which does not detect abrupt changes in ventricular filling pressures because of their long half-life [3-5].

Cardiac imaging tests: Cardiac imaging plays a central role in the diagnosis of $\mathrm{HF}$ as well as in monitoring and guiding therapy. Echocardiography is the preferred modality for reasons of accuracy, availability, safety and cost-effectiveness [52-54]. It may be complemented by other imaging modalities selected based on the ability to answer specific clinical questions while considering contraindications and risks $[55,56]$.

Echocardiography: Echocardiography is strongly recommended for all suspected patients because of its ability to confirm or exclude clinical diagnosis of LoHF, to assess SV and its variations, and to determine the cause of low-output state $[47,54,55]$. Transthoracic echocardiography should be performed as soon as possible following clinical diagnosis of low-cardiac output. Not only does it measure the extent of systolic and diastolic dysfunction, it also provides valuable information about ventricular morphology, valvular dysfunction, myocardial and pericardial disease and regional wall motion abnormalities [5]. Echocardiography evaluates systolic function by measuring LEVF, where $>45-50 \%$ is considered normal. On the other hand, diastolic function is evaluated using mitral in flow patterns, pulmonary vein flow and tissue Doppler at the mitral annulus, while CO and SV are evaluated using the Doppler principle. Pulmonary artery pressure (PAP) can be estimated by measuring regurgitate jet velocity. High PAP in the presence of dilated RV with septal flattening or bowing into the $\mathrm{LV}$ indicating acute increase in RV pressure raising clinical suspicion of $\mathrm{PE}$ as the cause of low output state $[47,54,56]$.

Chest X-ray: Chest $\mathrm{X}$-ray could be considered in patients suspected with LoHF. Important indicators that should considered for assessment include enlarged heart indicating cardiomegaly or LV hypertrophy; pulmonary venous congestion indicating elevated LV filling pressure; and pleural effusion indicating elevated LV pressure, pulmonary embolism or post-cardiac surgery( [45].

Coronary angiography: Indications for coronary angiography in LoHF patients should be in concordance with the recommendation of relevant consensus guidelines for HF [3-5]. In HF patients presenting with chest pain and evidence of ST-elevation myocardial infarction (STEMI) on ECG, revascularization using primary percutaneous coronary intervention should be performed as soon as possible. Coronary angiography should also be considered in patients with postcardiac arrest of ischemic aetiology, when there is evidence of HF and in patients who have recovered from low-output state when the cause has not been determined [5].

\section{Clinical management}

The presence of LoHF represents a very high-risk condition requiring prompt treatment but lacks standardized guidelines for clinical management [16]. Consequently, clinicians normally consider individual pathophysiology to select the most appropriate treatment strategy [57]. In acute LoHF patients, the 2016 ESC HF guidelines recommend the use of hemodynamic profiles (based on the presence or absence of congestion and adequacy of perfusion) to guide clinical management [5]. For LoHF patients in Profile L (no congestion but hypoperfused) and Profile C (both congestion and hypoperfused) who are in acute decompensation state, emergency treatment goals can include resuscitating patients, restoring oxygenation, improving organ perfusion and optimizing hemodynamic (stroke volume and $\mathrm{CO}$ ), and resolving symptoms. Other subsequent goals include optimal monitoring and establishing the underlying cause of low cardiac output and treating the cause if reversible [50,51,57]. At present, available therapeutic targets for LoHF are optimizing tissue oxygenation, stabilizing circulation and treating reversible causes of low-output state (Figure 3).

\section{Optimize tissue oxygenation (ventilatory strategies)}

Clinical management of LoHF patients often begins with the assessment of airway, breathing and circulation for evidence of peripheral hypoperfusion. Ventilator strategies such as oropharyngeal or nasopharyngeal airways are common adjuncts used to restore or maintain airway patency in LoHF patients with decreased levels of consciousness due to decreased cerebral perfusion. Additional endotracheal intubation should be considered if the patient remains with compromised airways [58]. If patients continues to remain hypoxic $\left(\mathrm{SaO}_{2}<95 \%\right)$, maximization of oxygen delivery using high flow oxygen, continuous positive airway pressure (CPAP) or non-invasive positive pressure ventilation (NIPPV) can be considered. In patients with no improvement, intubation or ventilation can be considered [59].

\section{Stabilize circulation}

Cardiac output $(\mathrm{CO})$ is a function of HR and SV. In turn, SV depends on four circulation variables - heart rate, preload, contractility and afterload. Optimizing all these variables will improve CO in LoHF patients $[49,51]$. In clinical setting, strategies to increase CO depend on the underlying cause and the affected circulation variable [16]. Clinical interventions include volume adjustment, pharmacological support and device therapy.

Heart Rate/Rhythm: As part of the body's physiological response, increasing HR increases CO. Too fast or slow HR has a detrimental effect on CO. In LoHF patients with tachycardia (too fast resting HR $>100 \mathrm{bpm}$ ) who are distressed, restless and dyspnoeic, morphine may 


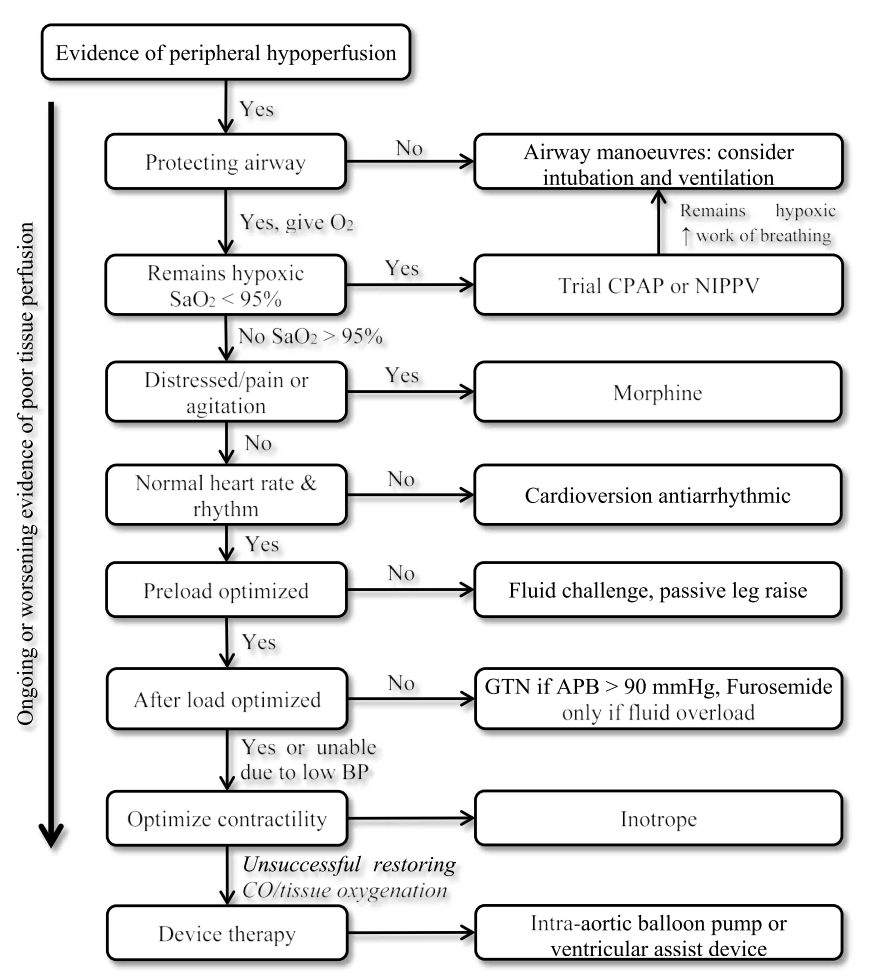

APB: Arterial Blood Pressure; BP: Blood Pressure; CPAP: Continuous Positive Airway Pressure; GTN Glyceryl trinitrate; NIPPV: Non-Invasive Positive Pressure Ventilation; $\mathrm{SaO}_{2}$ : Arterial Oxygen Saturation

Figure 3. Treatment algorithm for low-output heart failure

Treatment of LoHF targets improving tissue oxygenation and stabilizing circulation based on ongoing or worsening symptom of tissue perfusion. Treatment begins by improving ventilation using delivery of high flow oxygen, continuous positive airway pressure (CPAP) or non-invasive positive pressure ventilation (NIPPV). If unsuccessful, cardioversion or antiarrhythmic drugs are given to normalize heart rate, fluid challenge to optimize pre-load, and/or vasodilators and inotropes to manipulate and improve contractility respectively. If previous ventilation and medication are unsuccessful in restoring cardiac output and/or tissue oxygenation, device therapy using intra-aortic balloon pump or ventricular assist devices can be considered

be administered to relieve dyspnoea, pain and agitation as well as it is a mild venodilator for reducing afterload especially in CPAP or NIPPV patients [58]. If $\mathrm{HR}<40 \mathrm{bpm}$ with evidence of hemodynamic compromise and/or impaired CO, medication that increase $\mathrm{HR}$ (atropine and anticholinergics [Glycopyrrolate]) or interventions such as transcutaneous/transvenous pacing should be performed. Urgent electrical cardioversion should be considered in selected LoHF with ventricular/supraventricular tachycardia or rapid AF with evidence of cardiovascular compromise [4,5].

Optimize preload (Volume adjustments): Measurement of preload is essential for its optimization. It is recommended in patients with clinical evidence of impaired peripheral perfusion. A fluid challenge should be performed to assess preload responsiveness. Rapidly infusing $250 \mathrm{ml}$ fluid (crystalloid or colloid) for over five minutes and objectively assessing the effect on SV. If the effect is an increase or decrease $>10 \%$, the patient should continue receiving fluid boluses to optimise preload until they are no longer fluid responsive [16]. For patients with signs of congestion and pulmonary oedema who do not require fluid bolus, a passive leg raise can be done - lifting the patient's leg to 45 degrees to exclude the need for fluid challenge. If the response if favourable a real fluid challenge can be given [16].
Manipulate afterload (Pharmacological support): Afterload is the resistance against which the ventricle is ejecting blood, at times estimated as SVR. Afterload should be reduced in LoHF patients presenting with a high afterload, low $\mathrm{CO}$, evidence of poor peripheral perfusion and pulmonary oedema. Pharmacological support using vasodilators should be given to LoHF patients with systolic BP $\geq 110$ mmHg. In patients with systolic $\mathrm{BP}<90 \mathrm{mmHG}$ and mean arterial pressure $<65 \mathrm{mmHg}$, vasodilators are not recommended because of the risk of hypotension, which can complicate organ perfusion. In these patients, inotropes is recommended as the first line of treatment [51].

Improve contractility (Pharmacological support): If the patient persist with evidence of tissue hypoperfusion or reduced oxygen delivery despite interventions for heart rate, preload and afterload, treatment to improve contractility should be considered. Meanwhile, optimizing oxygen delivery should be continued to aim for haemoglobin $\geq 10 \mathrm{~g} /$ $\mathrm{dl}$ and ensuring optimal oxygen saturations $\left(\mathrm{SaO}_{2}\right)$. Factors adversely affecting myocardial contractility are hyperkalaemia, hypomagnesemia, hypocalcaemia, severe acidosis, hypoxia and hypoglycemia, which must be corrected. Inotropes are recommended to improve contractility and subsequently CO in LoHF patients with low BP and/or low CI in the presence of signs of poor peripheral perfusion or congestion [49,51]. However, pharmacological support using Dobutamine (an inotrope) should be used with caution in patients who have tachycardia or AF because it increases $\mathrm{AV}$ node conduction and can precipitate fast ventricular rhythms [5]. On the other hand, levosimendan is recommended in LoHF patients with acute myocardial ischemic or post cardiac surgery since it does not increase myocardial oxygen demand [5]. Long-term effect of inotropes could be detrimental and thus their use should be stopped once stability has been achieved. Vasopressors should not be the first-line medication in low-output states as they increase SVR and subsequently impair CO. However, a dual therapy of vasopressors and inotrope is recommended in patients having sepsis as the underlying cause of low-output state [51].

Device therapy: Device therapy should be considered in LoHF patients when optimal medical therapies have been unsuccessful in restoring $\mathrm{CO}$ and tissue oxygenation. Common device therapies include intra-aortic balloon pump (IABP) and ventricular assist device (VAD). The use of IABP is common in LoHF patients with ischemic heart disease, pre or post-percutaneous intervention or post-cardiac surgery. IABP comprises of a balloon inserted into the aorta through the femoral artery. The balloon inflates during diastole and deflates during systole to increase diastolic BP and consequently coronary perfusion, and reduces afterload thereby increasing $\mathrm{CO}$ [60]. On the other hand, the use of VAD is uncommon. It can only be used in specialist centres. It is commonly used as a bridge to cardiac transplantation in patients with favourable quality of life or to recovery in patients with acute myocarditis [61].

\section{Treating underlying causes}

Some causes of low-output state in patients with LoHF can be reversed with specific therapies. Reversible causes should be identified early during initial clinical evaluation. These causes include acute myocardial infarction, cardiac tamponade, tension pneumothorax, pulmonary embolism, and acute valve failure [16,17]. (Table 3).

\section{Meta-analysis of diagnosis and clinical management}

The basis of clinical diagnosis of LoHF has been echocardiographic evidence of LV/RV systolic dysfunction and/or LV diastolic dysfunction accompanied by evidence of reduced $\mathrm{CO}$ and $\mathrm{SvO}_{2}$ [5]. Hemodynamic 
Table 3. Therapies for causes of low-output stated in low-output heart failure

\begin{tabular}{|l|l|}
\hline Underlying Disease & Recommended Therapies \\
\hline Acute myocardial infarction & $\begin{array}{l}\text { Re-establish coronary circulation: primary percutaneous } \\
\text { coronary intervention if unavailable thrombolysis. } \\
\text { Antiplatelet therapy for patients with ST-segment elevation } \\
\text { myocardial infarction. }\end{array}$ \\
\hline Cardiac tamponade & $\begin{array}{l}\text { Percutaneous or surgical draining of pericardial effusion } \\
\text { causing hemodynamic compromise }\end{array}$ \\
\hline Tension pneumothorax & $\begin{array}{l}\text { Insert large cannula into the 2nd intercostal space in the } \\
\text { mid-clavicular line on the affected side to let air out and then } \\
\text { insert a chest drain }\end{array}$ \\
\hline Pulmonary embolism & Thrombolysis, thrombectomy/embolectomy \\
\hline Acute valve failure & Referral to the cardiothoracic surgeon \\
\hline
\end{tabular}

profiles based on measures of congestion and perfusion have been used to classify acute HF patients into four profiles: dry-warm (A), wet-warm (B), dry-cold (L) and wet-cold (C) and useful in identifying LoHF patients [51,53]. LoHF patients have been classified into Profiles (L) and (C) based on the presence/absence of congestion and/or the inadequacy of peripheral perfusion [53]. These two hemodynamic profiles have formed the basis for selecting patients with LoHF in clinical trials as well as provide simple bedside assessment to help classify patients at the time of presentation and to guide the selection of initial therapies $[51,62]$. The goal of the present meta-analysis is to aggregate published evidence of common diagnostic features and treatment outcomes for patients with LoHF.

\section{Search strategy}

Three major online databases (PubMed, EMBASE and Cochrane) were systematically searched since inception to December 2018 for studies investigating diagnosis and clinical management of LoHF. To avoid overlooking studies that did not mention LoHF in the title or abstract, the first 200 relevance-ranked articles retrieved with a full-text Google Scholar search were included. No publication time or language restrictions were applied. Additional studies were identified through a manual search of the list of references from the included studies as well as from relevant review articles, which were then subjected to the inclusion criteria. The search criteria included population of interest (patients with LoHF or LCOS), diagnostic tests of interest (echocardiography and hemodynamic profiles), and intervention of interest (ventilator strategies, volume adjustment, pharmacological support and device therapy). Studies were included if they met the following criteria: (a) included patients with LoHF; (b) diagnosed using echocardiography and hemodynamic profiles; (c) treated patients for hemodynamic stabilization; and (d) reported treatment outcomes. In cases of studies reporting duplicate data, only the study that provided the largest number of patients was included. Conference abstracts, case reports and review articles were excluded.

\section{Study selection}

Figure 4 illustrates the search and screening process used to include eligible studies. Two reviewers independently screened all the titles and abstracts retrieved from the systematic online search. Abstracts that included population, intervention and outcomes of interest were included for full-text search. Afterwards, the two reviewers also independently reviewed full-text articles against the inclusion criteria. In cases of discrepancy, it was resolved through discussion and consensus.

\section{Data collection}

Two reviewers independently extracted data from the included studies and any discrepancy was resolved through consensus. The main data extracted were echocardiographic and hemodynamic profile data, and treatment used and treatment outcome on hemodynamic (cardiac index, PCWP) and mortality. In addition to these main data, the two reviewers also extracted data on study characteristics, patients' characteristics and follow-up duration (Table 4).

\section{Statistical analysis}

Outcomes of interest reported in more than one study are cardiac index, PCWP and mortality. For each outcome, summary statistics (mean \pm standard deviation) before and after intervention was extracted or the difference between baseline and after treatment. These summary statistics were extracted separately for treatment and control/placebo groups. Diagnostic outcomes and treatment effects were measured by difference in means before and after intervention and associated $95 \%$ confidence interval. Forest plots were used to visually examine heterogeneity $\left(\mathrm{I}^{2}\right)$ across studies. Pooled diagnostic and treatment effect and associated 95\% confidence interval were estimated using fixed effect $\left(\mathrm{I}^{2}<49 \%\right)$ or random effect model $\left(\mathrm{I}^{2}>50 \%\right)$. P-value $>0.05$ was considered statistical significant.

\section{Results}

\section{Study characteristics}

Twelve (12) randomized controlled trials (RCTs) satisfied the inclusion criteria. Seven (7) studies [63-67, 69,70] enrolled LoHF patients and the remaining five (5) $[68,71-74]$ enrolled HF patients who have undergone cardiac surgery with low-cardiac output. The majority of published clinical trials (10) investigated medication comparing the effect of different types of inotropes on hemodynamic and prevention of death: dobutamine only [65], dobutamine and dopamine [63]; levosimendan and dobutamine [64,66-68,71], and levosimendan and placebo [72-74]. Of the remaining two clinical trials, each investigated vasodilator (nitroprusside) and placebo [69], and device therapy (IABP) and inotrope (levosimendan) alone or in combination with IAPB [70]. Altogether, the 12 clinical trials enrolled 3,738 patients, mean age 64 years (range $=55-74$ years), with a majority being male $(78 \%)$.

\section{Synthesis of results}

Diagnosis data on LoHF was inconsistent. Across the twelve clinical trials, no common definition of LoHF emerged that would have been

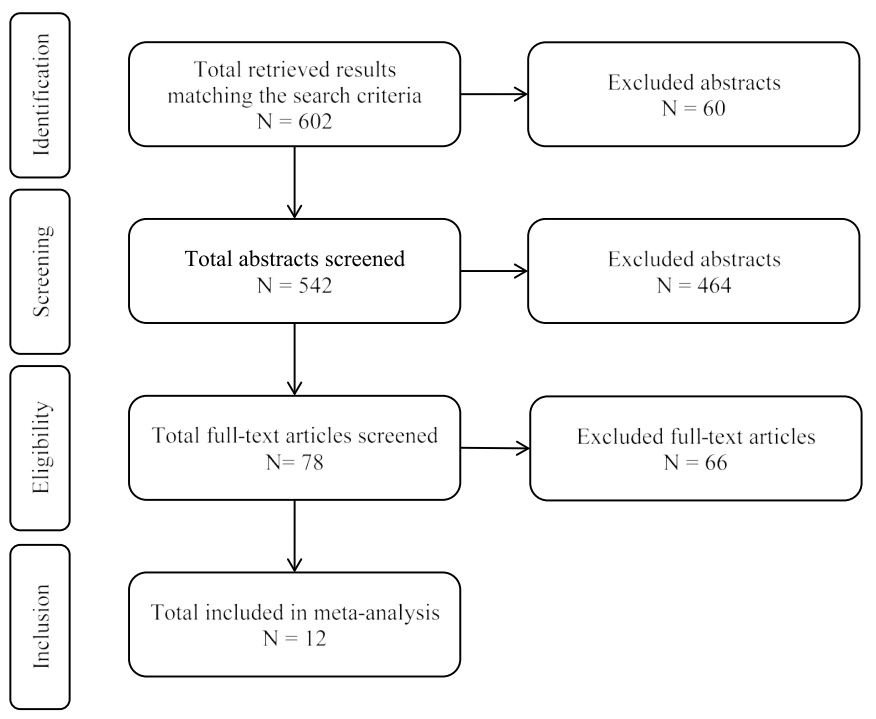

Figure 4. Flow diagram of literature search and inclusion process 
Table 4. Summary of included studies

\begin{tabular}{|c|c|c|c|c|c|c|}
\hline $\begin{array}{l}\text { 1st Author (year) } \\
\text { [Ref \#] }\end{array}$ & $\begin{array}{l}\text { Type of treatment/ } \\
\text { placebo }\end{array}$ & $\begin{array}{l}\text { No. of } \\
\text { Patients }\end{array}$ & $\begin{array}{c}\text { Mean } \\
\text { Age }\end{array}$ & Male (n) & $\begin{array}{l}\text { Diagnosis criteria used in } \\
\text { individual studies }\end{array}$ & Concluding remarks \\
\hline \multirow{2}{*}{$\begin{array}{l}\text { Loeb et al. (1977) } \\
{[63]}\end{array}$} & Dobutamine & 8 & 58 & 8 & \multirow{2}{*}{ Not reported } & \multirow{2}{*}{$\begin{array}{c}\text { Both dobutamine and dopamine improve CO, but dopamine could } \\
\text { elevate vascular resistance and LV filling pressure. }\end{array}$} \\
\hline & Dopamine & 5 & 58 & 5 & & \\
\hline \multirow{2}{*}{$\begin{array}{l}\text { Follath et al. (2002) } \\
{[64]}\end{array}$} & Dobutamine & 100 & 60 & 85 & \multirow{2}{*}{$\begin{array}{l}\mathrm{LVEF}<35 \% ; \mathrm{CI}<2.5 \mathrm{~L} / \mathrm{min} / \mathrm{m}^{2} \\
\quad \mathrm{PCWP}>15 \mathrm{mmHg}\end{array}$} & \multirow{2}{*}{$\begin{array}{l}\text { Levosimendan improved haemodynamic performance more than } \\
\text { dobutamine and with lower 180-days mortality. }\end{array}$} \\
\hline & Levosimendan & 103 & 58 & 91 & & \\
\hline $\begin{array}{l}\text { Nishimura et al. } \\
\text { (2002) [65] }\end{array}$ & Dobutamine & 32 & 74 & 30 & LVEF $<40 \%$ & $\begin{array}{c}\text { Dobutamine challenge can aid in selecting patients who would } \\
\text { benefit from an aortic valve operation. }\end{array}$ \\
\hline \multirow{2}{*}{$\begin{array}{l}\text { Adamopoulos et al. } \\
(2006)[66]\end{array}$} & Levosimendan & 23 & 71 & 62 & \multirow{2}{*}{$\mathrm{CI}<2.5 \mathrm{~L} / \mathrm{min} / \mathrm{m}^{2}$} & \multirow{2}{*}{$\begin{array}{l}\text { Levosimendan improves better hemodynamic and LV function } \\
\text { compared to dobutamine. }\end{array}$} \\
\hline & Dobutamine & 23 & 67 & 58 & & \\
\hline \multirow{2}{*}{$\begin{array}{l}\text { Mebazaa et al. } \\
(2007)[67]\end{array}$} & Levosimendan & 664 & 67 & 493 & \multirow{2}{*}{$\begin{array}{l}\mathrm{LVEF}<30 \% ; \mathrm{PCWP} \geq 18 \mathrm{mmHg} \\
\quad \mathrm{CI}<2.2 \mathrm{~L} / \mathrm{min} / \mathrm{m}^{2}\end{array}$} & \multirow{2}{*}{$\begin{array}{l}\text { Levosimendan did not significantly reduce } 180 \text {-days all-cause } \\
\text { mortality compared to dobutamine. }\end{array}$} \\
\hline & Dobutamine & 663 & 66 & 463 & & \\
\hline \multirow{2}{*}{$\begin{array}{l}\text { Levin et al. (2008) } \\
{[68]}\end{array}$} & Levosimendan & 69 & 62 & 43 & \multirow{2}{*}{$\mathrm{CI}<2.2 \mathrm{~L} / \mathrm{min} / \mathrm{m}^{2}$} & \multirow{2}{*}{$\begin{array}{l}\text { Levosimendan proved more effective than dobutamine in improving } \\
\text { hemodynamic and reducing mortality. }\end{array}$} \\
\hline & Dobutamine & 68 & 62 & 41 & & \\
\hline \multirow{2}{*}{$\begin{array}{l}\text { Mullens et al. } \\
(2008)[69]\end{array}$} & Nitroprusside & 78 & 55 & 78 & \multirow{2}{*}{$\mathrm{CI}<2.5 \mathrm{~L} / \mathrm{min} / \mathrm{m}^{2}$} & \multirow{2}{*}{$\begin{array}{l}\text { Vasodilator plus optimal medical therapy has favourable long-term } \\
\text { outcomes irrespective of inotropic support. }\end{array}$} \\
\hline & Placebo & 97 & 55 & 66 & & \\
\hline \multirow{3}{*}{$\begin{array}{l}\text { Lomivorotov et al. } \\
(2012)[70]\end{array}$} & IABP & 30 & 57 & 29 & \multirow{3}{*}{$\begin{array}{l}\mathrm{CI}<2.0 \mathrm{~L} / \mathrm{min} / \mathrm{m}^{2} ; \mathrm{SvO}_{2}<60 \% \text { on } \\
\text { minimal inotropic support }\end{array}$} & \multirow{3}{*}{$\begin{array}{l}\text { Infusion of levosimendan after anaesthesia in cardiac surgery } \\
\text { improves haemodynamic compared with a preoperative IABP }\end{array}$} \\
\hline & IABP/Levosimendan & 30 & 58 & 29 & & \\
\hline & Levosimendan & 30 & 57 & 24 & & \\
\hline \multirow{2}{*}{$\begin{array}{l}\text { Alvarez et al. } \\
(2013)[71]\end{array}$} & Levosimendan & 12 & 73 & 7 & \multirow{2}{*}{$\mathrm{CI}<2.2 \mathrm{~L} / \mathrm{min} / \mathrm{m}^{2}$} & \multirow{2}{*}{$\begin{array}{l}\text { Levosimendan vasodilates hepatic and portal venous system while } \\
\text { dobutamine improve portal venous blood low. }\end{array}$} \\
\hline & Dobutamine & 13 & 72 & 6 & & \\
\hline \multirow{2}{*}{$\begin{array}{l}\text { Cholley et al. } \\
(2017)[72]\end{array}$} & Levosimendan & 167 & 69 & 139 & \multirow{2}{*}{$\mathrm{LVEF}<40 \%$} & \multirow{2}{*}{$\begin{array}{l}\text { In post-operative CABG levosimendan has no significant effect on } \\
\text { preventing mortality compared to placebo }\end{array}$} \\
\hline & Placebo & 168 & 67 & 143 & & \\
\hline \multirow{2}{*}{$\begin{array}{l}\text { Landoni et al. } \\
(2017)[73]\end{array}$} & Levosimendan & 248 & 66 & 159 & \multirow{2}{*}{$\begin{array}{l}\text { LVEF }<25 \% \text {; need for inotropic } \\
\text { support }\end{array}$} & \multirow{2}{*}{$\begin{array}{l}\text { In post-operative CABG patients, levosimendan plus standard care } \\
\text { did not lower } 30 \text {-day mortality than placebo }\end{array}$} \\
\hline & Placebo & 258 & 66 & 168 & & \\
\hline \multirow{2}{*}{$\begin{array}{l}\text { Mehta et al. (2017) } \\
{[74]}\end{array}$} & Levosimendan & 428 & 65 & 347 & \multirow{2}{*}{ LVEF $<40 \%$} & \multirow{2}{*}{$\begin{array}{l}\text { Prophylactic levosimendan does not lower did not result in a rate of } \\
\text { the short-term mortality compared to placebo. }\end{array}$} \\
\hline & Placebo & 421 & 65 & 332 & & \\
\hline
\end{tabular}

CI: Cardiac Index; IABP: Intra-aortic Balloon Pump; LVEF: Left Ventricular Ejection Fraction; PCWP: Pulmonary Capillary Wedge Pressure

useful to guide diagnosis. Hemodynamic criteria used for inclusion of patients in the trials included $\mathrm{CI}<2.0 \mathrm{~L} / \mathrm{min} / \mathrm{m}^{2}$ [70], $\mathrm{CI}<2.2 \mathrm{~L} / \mathrm{min} /$ $\mathrm{m}^{2}[67,68,71]$ or $\mathrm{CI}<2.5 \mathrm{~L} / \mathrm{min} / \mathrm{m}^{2}[64,66,69]$ and PCWP $>15 \mathrm{mmHg}$ [64] or $\geq 18 \mathrm{mmHg}$ [67]. The definition also varied across studies - postoperative condition with hypotension (systolic $\mathrm{BP}<90 \mathrm{mmHg}$ for $>30$ minute) or the need for inotropic support to maintain systolic BP $>90$ $\mathrm{mmHg}$ and end-organ hypoperfusion (cold peripheries, urine output $<$ $30 \mathrm{ml} /$ hour) [70]. Cardiogenic shock has been described as a complex syndrome involving a cascade of acute LV dysfunction, decreased CO, hypotension and tissue hypoperfusion [67].

Figures 5 and 6 show forest plots for standardized mean of cardiac index at baseline and following inotrope or vasodilator therapy respectively. The baseline cardiac index increased from a mean of 1.93 (95\% CI: $1.91-1.95)$ to post-treatment mean of 2.82 (95\% CI: 2.80 2.84). Figure 7 shows a forest plot for standard mean difference (SMD) of cardiac index after treatment with levosimendan and dobutamine. Levosimendan achieve higher cardiac index compared to dobutamine (SMD: 2.82; 95\% CI: 2.54-3.10). As a prophylactic against LoHF in postoperative patients, levosimendan infusion after anaesthesia achieved a higher cardiac index (2.57) compared to pre-operative IABP (2.3) or with a combination of levosimendan (2.4). Figure 8 shows a forest plot of mortality rate between levosimendan and placebo. Levosimendan had lower mortality rate compared to placebo (Odds Ratio [OR]: 0.83; 95\% CI: 0.59-1.18) but the difference was not statistically significant $(\mathrm{p}=0.30)$. Final, Figure 9 further shows Levosimendan has a lower mortality rate compared to dobutamine (OR: 0.65 ; 95\% CI: 0.39-1.08) but the difference was not statistically significant $(\mathrm{p}=0.10)$.

\section{Discussion of findings}

This systematic review and meta-analysis assessed common diagnostic features, and treatment outcomes of medical and device
Mean and $95 \% \mathrm{Cl}$ - Baseline Cardiac Index

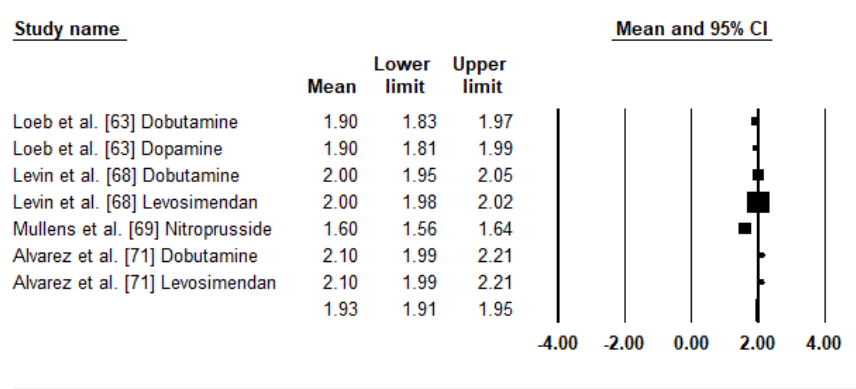

Figure 5. Mean baseline cardiac index

Mean and 95\% Cl: Post-treatment Cardiac Index

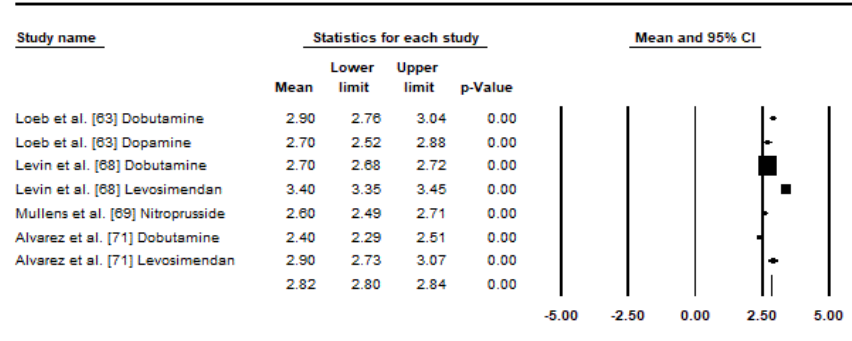

Figure 6. Mean post-treatment cardiac index

therapy (IABP) on LoHF patients. The results indicates that LoHF patients lack widely accepted or standardized diagnosis features. Although LoHF patients could exhibit several features including cardiac index, PCWP, systolic $\mathrm{BP}$ and $\mathrm{SvO}_{2}$ to suggest or support clinical diagnosis, all these features have different cut-off values across 
Std Mean Difference in Levosimendan vs. Dobutamine Post-treatment Cardiac Index

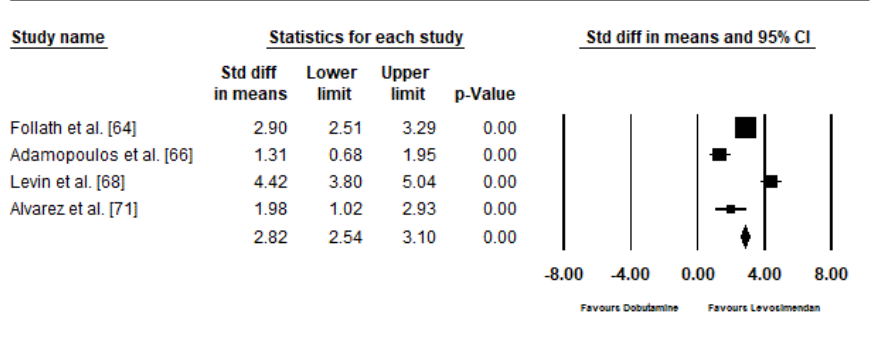

Figure 7. Mean difference in cardiac index between levosimendan and dobutamine

Odds Ratio and $95 \% \mathrm{Cl}$ : Mortality Rate - Levosimendan vs. Placebo

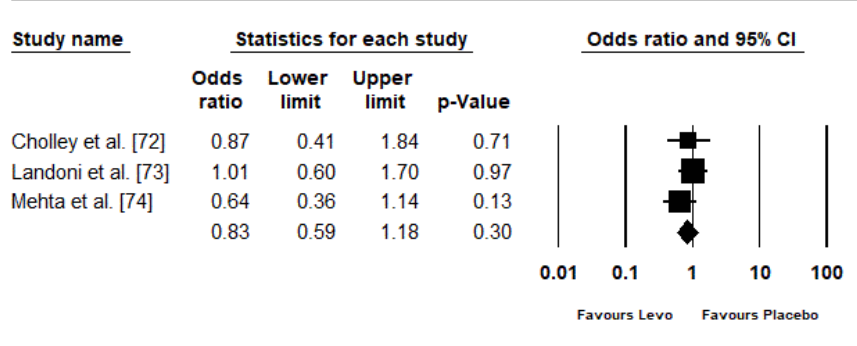

Figure 8. Mortality rate between levosimendan and placebo

Odds Ratio and $95 \% \mathrm{Cl}$ : Mortality Rate - Levosimendan vs. Dobutamine

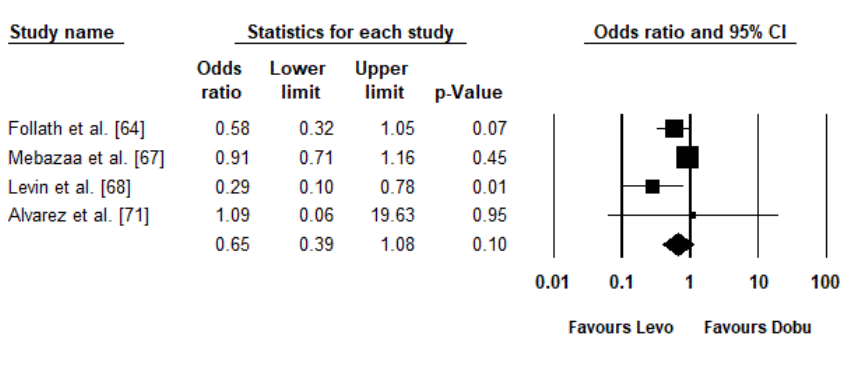

$1 \wedge 2=52.39 ; \mathrm{p}=0.098$

Figure 9. Mortality rate between levosimendan and dobutamine

studies. Cardiac index, which is the most common clinical feature demonstrating low-output state in LoHF, has three cut-off values: $<2.0$ $\mathrm{L} / \mathrm{min} / \mathrm{m}^{2}[70],<2.2 \mathrm{~L} / \mathrm{min} / \mathrm{m}^{2}[67,68,71]$ or $<2.5 \mathrm{~L} / \mathrm{min} / \mathrm{m}^{2}[64,66,69]$. Inotropic support emerged as a very common intervention for improving perfusion and normalizing cardiac output in LoHF patients.

Inotropic medication such as levosimendan, dobutamine, dopamine, vasodilator (nitroprusside) and IABP significantly improved CI between baseline and post-treatment. In terms of inotropes, levosimendan is more effective in improving hemodynamic stability and a better prophylactic against short-term death (30-day mortality) than dobutamine. In addition, inotropes can act as prophylactic against the development of post-operative LoHF. On the other hand, while inotropes improve hemodynamic and normalize cardiac output, they do not provide any significantly better protection against mortality irrespective of the type of inotrope used.

The role of inotropes in the treatment of LoHF has been supported by a previous review of inotropic agents and vasodilator strategies for the treatment of cardiogenic shock and LCOS [75]. The review reported inotropes improve hemodynamic, adverse events in post-operative
LCOS and reduced mortality. Newer inotropes such as levosimendan (a calcium sensitizer and inodilator) is a positive inotrope has some vasodilatory properties [67]. It can also be considered as a selective liver vasodilator, which can improve portal venous flow via hepatic artery and portal venous flow compared to dobutamine that can only improve portal venous flow without vasodilating the hepatic artery [71]. Levosimendan also does not increase myocardial oxygen demand and recommended over dobutamine in LoHF patients with acute myocardial ischemic or post cardiac surgery [5]. For post-operative LoHF, the protective effect of inotropes against short-term mortality rate (30-day mortality) remains insignificant compared to placebo [75].

The present systematic review and meta-analysis has some important limitations. LoHF may occur in secondary to underlying cardiac disease such as acute myocardial infarction or post-operative. Most of the studies included investigated post-operative LoHF with fewer presentation of LoHF from other causes. Most of the studies focused on two inotropes (Levosimendan and dobutamine), limiting the understanding of other inotropes as well as other therapies such as device therapies. In some trials, the analysis were at risk of misclassification bias due to a significant number of patients lost to follow-up. Since most of the trials do not report pair-wise pre- and post-intervention difference with associated standard deviation, pre and post-intervention difference with standard deviation, pre- and post-intervention outcomes measures as independent, this obtaining sider confidence intervals for treatment effect with an associated standard deviation.

\section{Conclusion}

Low-output heart failure (LoHF) is a clinical syndrome characterized by decreased cardiac output accompanied by end-organ hypoperfusion. It is an uncommon form of heart failure in the general population but prevalent in post-operation HF patients. Its aetiology is heterogeneous, consisting of various conditions causing low-output state and cardiac surgery. The main pathophysiologic mechanisms are LV systolic and/or diastolic dysfunction, and RV dysfunction caused by changes in heart rate, preload, afterload and/or contractility. General risk factors for LoHF include Chagas disease, depressed ejection fraction, and renal dysfunction while in post-operative patients include impaired LV function, incomplete revascularization, older age, and presence of diabetes and renal dysfunction. Diagnosis lacks standardized guidelines and dependent on accepted collection of hemodynamic and physiologic aberrations including conditions causing low-output state. Patient history and physical examination help to assess hemodynamic status and recognize low-output state while echocardiography confirms ventricular dysfunction (HF) and low cardiac output. Other tests to support diagnosis or establish the cause of low-output state include electrocardiogram and basic laboratory tests (blood, serum electrolyte, urea and creatinine, liver test, thyroid function and serum natriuretic peptides) and cardiac imaging (chest $\mathrm{x}$-ray or coronary angiography). Treatment lacks established guidelines but depends on the assessment of individual pathophysiology to select the most appropriate treatment strategy. Treatment includes ventilator strategies to improve heart rate and rhythm; volume adjustment to optimize preload; pharmacological support (inotropes and vasodilators) to manipulate afterload and improve contractility; and device therapy (intra-aortic balloon pump or ventricular assist device) when these strategies do not restore cardiac output. In selected patients, therapies to reverse underlying disease, can restore cardiac output. 


\section{References}

1. Inamdar A, Inamdar A (2016) Heart failure diagnosis, management and utilization. $J$ Clin Med 5: 62. [Crossref]

2. Dassanayaka S, Jones SP (2015) Recent developments in heart failure. Circ Res 117: e58-63. [Crossref]

3. McMurray JJ, Adamopoulos S, Anker SD, Auricchio A, Bohm M, et al. (2012) Guidelines for the diagnosis and treatment of acute and chronic heart failure 2012: The Task Force for the Diagnosis and Treatment of Acute and Chronic Heart Failure 2012 of the European Society of Cardiology. Developed in collaboration with the Heart Failure Association (HFA) of the ESC. Eur J Heart Fail 14: 803-869.

4. Yancy CW, Jessup M, Bozkurt B, Butler J, Casey DE, et al. (2013) 2013 ACCF/AHA guideline for the management of heart failure: a report of the American College of Cardiology Foundation/American Heart Association Task Force on Practice Guidelines. $J$ Am Coll Cardiol 62: e147-239.

5. Ponikowski P, Voors AA, Anker SD, Bueno H, Cleland JG, et al. (2016) 2016 ESC Guidelines for the diagnosis and treatment of acute and chronic heart failure: The Task Force for the diagnosis and treatment of acute and chronic heart failure of the European Society of Cardiology (ESC) Developed with the special contribution of the Heart Failure Association (HFA) of the ESC. Eur Heart J 37: 2129-2200.

6. Masse L, Antonacci M (2005) Low cardiac output syndrome: identification and management. Crit Care Nurs Clin 17: 375-383. [Crossref]

7. Poppas A, Rounds S (2002) Congestive heart failure. Am J Respir Crit Care Med 165: 4-8. [Crossref]

8. Nieminen MS, Bohm M, Cowie MR, Drexler H, Filippatos GS, et al. (2005) Executive summary of the guidelines on the diagnosis and treatment of acute heart failure: The Task Force on Acute Heart Failure of the European Society of Cardiology. Eur Heart J 26: 384-416

9. Parr GV, Blackstone EH, Kirklin JW (1975) Cardiac performance and mortality early after intracardiac surgery in infants and young children. Circulation 51: 867-874.

10. Wernovsky G, Wypij D, Jonas RA, Mayer Jr JE, Hanley FL, et al. (1995) Postoperative course and hemodynamic profile after the arterial switch operation in neonates and infants: a comparison of low-flow cardiopulmonary bypass and circulatory arrest. Circulation 92: 2226-2235.

11. Hogue CW Jr, Sundt T 3rd, Barzilai B, Schectman KB, Dávila-Román VG (2001) Cardiac and neurologic complications identify risks for mortality for both men and women undergoing coronary artery bypass graft surgery. Anaesthesiology 95: 10741078.

12. Rao V, Ivanov J, Weisel RD, Ikonomidis JS, Christakis GT, et al. (1996) Predictors of low cardiac output syndrome after coronary artery bypass. $J$ Thorac Cardiovasc Surg 112: 38-51. [Crossref]

13. Arribas Leal JM, Pascual DA, Tornel PL, Gutierrez F, Garcia-Puente JJ, et al. (2010) Epidemiology and new predictors of low cardiac output syndrome after isolated coronary artery bypass grafting. Eur Heart $J 31:$ 68-69.

14. Sá MP, Nogueira JR, Ferraz PE, Figueiredo OJ, Cavalcante WC, et al. (2012) Risk factors for low cardiac output syndrome after coronary artery bypass grafting surgery. Braz J Cardiovasc Surg 27: 217-223.

15. Algarni KD, Maganti M, Yau TM (2011) Predictors of low cardiac output syndrome after isolated coronary artery bypass surgery: trends over 20 years. Ann Thorac Surg 92: $1678-1684$.

16. Chandler HK, Kirsch R (2016) Management of the low cardiac output syndrome following surgery for congenital heart disease. Curr Cardiol Rev 12: 107-111.

17. Lomivorotov VV, Efremov SM, Kirov MY, Fominskiy EV, Karaskov AM (2017) Lowcardiac-output syndrome after cardiac surgery. J Cardiothorac Vasc Anesth31: 291308. [Crossref]

18. Tibby SM., Murdoch IA (2003) Monitoring cardiac function in intensive care. Arch Dis Child 88: 46-52. [Crossref]

19. Carcillo JA, Field AI (2002) Clinical practice parameters for hemodynamic support of paediatric and neonatal patients in septic shock. Crit Care Med 30: 1365-1378.

20. Chiong M, Wang ZV, Pedrozo Z, Cao DJ, Troncoso R, et al. (2011) Cardiomyocyte death: mechanisms and translational implications. Cell death \& disease 2: e244.

21. Tavernarakis N (2007) Cardiomyocyte necrosis: alternative mechanisms, effective interventions. Biochimica et Biophysica Acta (BBA)-Molecular Cell Research 1773: 480-482.
22. Dorn GW (2008) Apoptotic and non-apoptotic programmed cardiomyocyte death in ventricular remodelling. Cardiovasc Res 81: 465-473.

23. Richard Conti C (1991) The stunned and hibernating myocardium: a brief review. Clin Cardiol 14: 708-712. [Crossref]

24. Alsaddique AA, Royse CF, Fouda MA, Royse AG (2012) Diastolic heart failure after cardiac surgery. In Coronary Artery Disease-Current Concepts in Epidemiology, Pathophysiology, Diagnostics and Treatment 2012. InTech.

25. Kass DA, Bronzwaer JG, Paulus WJ (2004) What mechanisms underlie diastolic dysfunction in heart failure? Circ Res 94: 1533-1542.

26. Borlaug BA, Paulus WJ (2010) Heart failure with preserved ejection fraction pathophysiology, diagnosis, and treatment. Eur Heart J 32: 670-679.

27. Ramirez-Correa GA, Murphy AM (2007) Is Phospholamban or Troponin I the "prima Donna" in $\beta$-adrenergic Induced Lusitropy? Circ Res 101: 326-327. [Crossref]

28. Paulus WJ, Vantrimpont PJ, Shah AM (1994) Acute effects of nitric oxide on lef ventricular relaxation and diastolic distensibility in humans. Assessment by bicoronary sodium nitroprusside infusion. Circ 89: 2070-2078.

29. Lappas DG, Skubas NJ, Lappas GD, Ruocco E, Tambassis E, et al. (1999) Prevalence of Left Ventricular Diastolic Filling Abnorrnalities in Adult Cardiac Surgical Patients An Intraoperative Echo cardiographic Study. Semin Thorac Cardiovasc Surg 11: 125133.

30. Shi Y, Denault AY, Couture P, Butnaru A, Carrier M, et al. (2006) Biventricular diastolic filling patterns after coronary artery bypass graft surgery. $J$ Thorac Cardiovasc Surg 131: 1080-1086.

31. Bossone E, Bodini BD, Mazza A, Allegra L (2005) Pulmonary arterial hypertension the key role of echocardiography. Chest 127: 1836-1843. [Crossref]

32. Zochios V, Jones N (2014) Acute right heart syndrome in the critically ill patient. Heart lung vessel 6: 157-170. [Crossref]

33. Fletcher N, Geisen M, Meeran H, Spray D, Cecconi M (2015) Initial clinical experience with a miniaturized transesophageal echocardiography probe in a cardiac intensive care unit. J Cardiothorac Vasc Anesth 29: 582-587.

34. Brooks H, Kirk ES, Vokonas PS, Urschel CW, Sonnenblick EH (1971) Performance of the right ventricle under stress: Relation to right coronary flow. $J$ Clin Invest 50 : 2176-2183

35. Price LC, Wort SJ, Finney SJ, Marino PS, Brett SJ (2010) Pulmonary vascular and right ventricular dysfunction in adult critical care: Current and emerging options for management: A systematic literature review. Crit Care 14: R169. [Crossref]

36. Pfisterer M (2003) Right ventricular involvement in myocardial infarction and cardiogenic shock. Lancet 362: 392-394.

37. Ochiai ME, Cardoso JN, Vieira KR, Lima MV, Brancalhao EC, et al. (2011) Predictors of low cardiac output in decompensated severe heart failure. Clinics 66: 239-244. [Crossref]

38. Kim DK, Yoo KJ, Hong YS, Chang BC, Kang MS (2007) Clinical outcome of urgent coronary artery bypass grafting. J Korean Med Sci 22: 270-276.

39. Maganti MD, Rao V, Borger MA, Ivanov J, David TE (2005) Predictors of low cardiac output syndrome after isolated aortic valve surgery. Circulation 112: I-448.

40. Lomivorotov VV, Efremov SM, Boboshko VA, Nikolaev DA, Vedernikov PE, et al (2013) Evaluation of nutritional screening tools for patients scheduled for cardiac surgery. Nutrition 29: 436-442.

41. Hernández-Leiva E, Dennis R, Isaza D, Umaña JP (2013) Hemoglobin and B-type natriuretic peptide preoperative values but not inflammatory markers, are associated with postoperative morbidity in cardiac surgery: A prospective cohort analytic study. $J$ Cardiothorac Surg 8:170. [Crossref]

42. Lomivorotov VV, Efremov SM, Boboshko VA, Leyderman IN, Lomivorotov VN, et al (2011) Preoperative total lymphocyte count in peripheral blood as a predictor of poor outcome in adult cardiac surgery. J Cardiothorac Vasc Anesth 25: 975-980.

43. Cuthbertson BH, Croal BL, Rae D, Gibson PH, McNeilly JD, et al. (2009) N-terminal pro-B-type natriuretic peptide levels and early outcome after cardiac surgery: A prospective cohort study. BrJ Anaesth 103: 647-653.

44. Hutfless R, Kazanegra R, Madani M, Bhalla MA, Tulua-Tata A, et al. (2004) Utility of B-type natriuretic peptide in predicting postoperative complications and outcomes in patients undergoing heart surgery. J Am Coll Cardiol 43: 1873-1879.

45. Gheorghiade M, Abraham WT, Albert NM, Gattis Stough W, Greenberg BH, et al (2007) Relationship between admission serum sodium concentration and clinica outcomes in patients hospitalized for heart failure: an analysis from the OPTIMIZE-HF registry. Eur Heart $J$ 28: 980-988. 
46. Abraham WT, Adams KF, Fonarow GC, Costanzo MR, Berkowitz RL, et al. (2005) In-hospital mortality in patients with acute decompensated heart failure requiring intravenous vasoactive medications: an analysis from the Acute Decompensated Heart Failure National Registry (ADHERE). J Am Coll Cardiol 46: 57-64.

47. Grady KL, Dracup K, Kennedy G, Moser DK, Piano M, et al. (2000) Team management of patients with heart failure: a statement for healthcare professionals from the Cardiovascular Nursing Council of the American Heart Association. Circulation 102: 2443-24456.

48. Stevenson LW, Perloff JK (1989) The limited reliability of physical signs for estimating hemodynamics in chronic heart failure. Jama 261: 884-888.

49. Nohria A, Tsang SW, Fang JC, Lewis EF, Jarcho JA, et al. (2003) Clinical assessment identifies hemodynamic profiles that predict outcomes in patients admitted with heart failure. J Am Coll Cardiol 41: 1797-1804.

50. Forrester JS, Diamond G, Chatterjee K, Swan HJ (1976) Medical therapy of acute myocardial infarction by application of hemodynamic subsets. $N$ Engl J Med 295: 1356-1362.

51. Nohria A, Lewis E, Stevenson LW (2002) Medical management of advanced heart failure. Jama 287: 628-640. [Crossref]

52. Kirkpatrick JN, Vannan MA, Narula J, Lang RM (2007) Echocardiography in heart failure: applications, utility, and new horizons. J Am Coll Cardiol 50: 381-396. [Crossref]

53. Nagueh SF, Bhatt R, Vivo RP, Krim SR, Sarvari SI, et al. (2011) Echocardiographic evaluation of hemodynamics in patients with decompensated systolic heart failure. Circ Cardiovasc Imaging 4: 220-227.

54. Lang RM, Badano LP, Mor-Avi V, Afilalo J, Armstrong A, et al. (2015) Recommendations for cardiac chamber quantification by echocardiography in adults: an update from the American Society of Echocardiography and the European Association of Cardiovascular Imaging. Eur Heart J Cardiovasc Imaging 16: 233-271.

55. Garbi M, McDonagh T, Cosyns B, Bucciarelli-Ducci C, Edvardsen T, et al. (2014) Appropriateness criteria for cardiovascular imaging use in heart failure: report of literature review. Eur Heart J Cardiovasc Imaging 16: 147-153.

56. Gimelli A, Lancellotti P, Badano LP, Lombardi M, Gerber B, et al. (2014) Non-invasive cardiac imaging evaluation of patients with chronic systolic heart failure: a report from the European Association of Cardiovascular Imaging (EACVI). Eur Heart J 35: 3417 3425 .

57. Vazir A, Cowie MR (2012) Assessing acute decompensated heart failure: Strategies and tools. Eur Cardiol 8: 128-133.

58. Gray A, Goodacre S, Newby DE, Masson M, Sampson F, et al. (2008) Noninvasive ventilation in acute cardiogenic pulmonary edema. $N$ Engl J Med 359: 142-151.

59. Cotter G, Cotter OM, Kaluski E (2008) Hemodynamic monitoring in acute heart failure. Crit Care Med 36: S40-S43. [Crossref]

60. Lewis PA, Ward DA, Courtney MD (2009) The intra-aortic balloon pump in heart failure management: implications for nursing practice. Aust Crit Care 22: 125-131.

61. Slaughter MS, Singh R (2012) The role of ventricular assist devices in advanced heart failure. Revista Española de Cardiologia 65: 982-985. [Crossref]
62. Shah MR, Hasselblad V, Stinnett SS, Gheorghiade M, Swedberg K, et al. (2001) Hemodynamic profiles of advanced heart failure: association with clinical characteristics and long-term outcomes. J Card Fail 7: 105-113.

63. Loeb HS, Bredakis J, Gunner RM (1977) Superiority of dobutamine over dopamine for augmentation of cardiac output in patients with chronic low output cardiac failure. Circulation 55: 375-378.

64. Follath F, Cleland JG, Just H, Papp JG, Scholz H, et al. (2002) Efficacy and safety of intravenous levosimendan compared with dobutamine in severe low-output heart failure (the LIDO study): a randomised double-blind trial. The Lancet 360: 196-202.

65. Nishimura RA, Grantham JA, Connolly HM, Schaff HV, Higano ST, et al. (2002) Low-output, low-gradient aortic stenosis in patients with depressed left ventricular systolic function: the clinical utility of the dobutamine challenge in the catheterization laboratory. Circulation 106: 809-813.

66. Adamopoulos S, Parissis JT, Iliodromitis EK, Paraskevaidis I, Tsiapras D, et al. (2006) Effects of levosimendan versus dobutamine on inflammatory and apoptotic pathways in acutely decompensated chronic heart failure. Am J Cardiol 98: 102-106.

67. Mebazaa A, Nieminen MS, Packer M, Cohen-Solal A, Kleber FX, et al. (2007) Survive Investigators. Levosimendan vs dobutamine for patients with acute decompensated heart failure: the SURVIVE Randomized Trial. Jama 297: 1883-1891.

68. Levin RL, Degrange MA, Porcile R, Salvagio F, Blanco N, et al. (2008) The calcium sensitizer levosimendan gives superior results to dobutamine in postoperative low cardiac output syndrome. Revista Española de Cardiología (English edition) 61: 471479 .

69. Mullens W, Abrahams Z, Francis GS, Skouri HN, Starling RC, et al. (2008) Sodium nitroprusside for advanced low-output heart failure. J Am Coll Cardiol 52: 200-207. [Crossref]

70. Lomivorotov VV, Boboshko VA, Efremov SM, Kornilov IA, Chernyavskiy AM, et al. (2012) Levosimendan versus an intra-aortic balloon pump in high-risk cardiac patients. J Cardiothorac Vasc Anesth 26: 596-603. [Crossref]

71. Alvarez J, Baluja A, Selas S, Otero P, Rial M, et al. (2013) A comparison of doubutamine and levosimendan $\mathrm{n}$ hepatic blood flow in patients with a low cardiac output state after cardiac surgery: a randomised controlled study. Anaesth Intensive Care 41: 719-727.

72. Cholley B, Caruba T, Grosjean S, Amour J, Ouattara A, et al. (2017) Effect of levosimendan on low cardiac output syndrome in patients with low ejection fraction undergoing coronary artery bypass grafting with cardiopulmonary bypass: the LICORN randomized clinical trial. Jama 318: 548-556. [Crossref]

73. Landoni G, Lomivorotov VV, Alvaro G, Lobreglio R, Pisano A, et al. (2017) Levosimendan for hemodynamic support after cardiac surgery. $N$ Engl J Med 376 : 2021-2031. [Crossref]

74. Mehta RH, Leimberger JD, Van Diepen S, Meza J, Wang A, et al. (2017) Levosimendan in patients with left ventricular dysfunction undergoing cardiac surgery. $N$ Engl J Med 376: 2032-2042. [Crossref]

75. Schumann J, Henrich EC, Strobl H, Prondzinsky R, Weiche S, et al. (2018) Inotropic agents and vasodilator strategies for the treatment of cardiogenic shock or low cardiac output syndrome. The Cochrane Library. 2 : 1-10. [Crossref]

Copyright: (C2019 Albakri A. This is an open-access article distributed under the terms of the Creative Commons Attribution License, which permits unrestricted use, distribution, and reproduction in any medium, provided the original author and source are credited. 